\title{
PELATIHAN ASSESSMENT FOR LEARNING BERBANTUAN PROGRAM TRY OUT DAN WEB VOTING BAGI GURU FISIKA DI KOTA MALANG
}

\author{
Sentot Kusairi $^{1 *}$, Lia Yuliati ${ }^{2}$, Asim $^{3}$, Nurul Hidayat ${ }^{4}$, Sujito $^{5}$ \\ 1,2,3,4,5Fakultas Matematika dan Ilmu Pengetahuan Alam, Universitas Negeri Malang \\ *Email Korespondensi: sentot.kusairi.fmipa@um.ac.id
}

\begin{abstract}
ABSTRAK
Kegiatan pelatihan ini bertujuan meningkatkan kapasitas guru-guru fisika SMA dalam menyelenggarakan kegiatan asesmen utamanya assessment for learningberbantuan aplikasi komputer. Target kegiatan adalah meningkatkan wawasan tentang peranan assessment for learning dalam pembelajaran, keterampilan menggunakan aplikasi Webvoting, dan memanfaatkan aplikasi Tryout dalam pembelajaran. Tahapan pertama pelatihan dan workshop adalah diskusi dan sharing berkaitan dengan pelaksanaan dan kendala penilaian pada saat ini. Guru fisika menyepakati bahwa pelaksanaan assessment for learning tidak mudah dilakukan dan memerlukan penggunaan teknologi. Pada tahapan ini dilakukan pula pemaparan tentang peranan asesment for learning dalam pembelajaran dengan cara mengimplementasikan Five Key Element of Assessment for Learning. Pada tahapan berikutnya, dilanjutkan dengan pelatihan penggunaan aplikasi Tryout dan Aplikasi Webvooting. Guru fisika telah trampil dalam mengimplementasikan assessment for learning di kelas, namun penggunaan aplikasi Tryout dan webvoting membutuhkan penyiapan instrument berupa soal pilihan ganda isomorfik yang memerlukan pelatihan tersendiri. Penuangan hasil implementasi dalam bentuk karya ilmiah juga masih memerlukan pendampingan secara berkelanjutan.
\end{abstract}

Kata kunci : assessment for learning, guru fisika, SMA

\section{ABSTRACT}

This training activity aims to increase the capacity of high school physics teachers in organising their main assessment activities computer-assisted assessment for learning. The target of the activity is to increase insights about the role of assessment for learning in learning, skills using the Webvoting application, and utilising Tryout applications in teaching. The first stage of training and workshops is discussion and sharing related to the implementation and assessment constraints at the moment. Physics teachers agree that the implementation of assessment for learning is not easy to do and requires the use of technology. At this stage, there is also a presentation on the role of assessment for learning in teaching by implementing the Five Key Element of Assessment for Learning. In the next stage, proceed with training in using the Tryout application and webvooting Application. Physics teachers have been skilled in implementing assessment for learning in the classroom. However, the use of Tryout and webvoting applications requires the preparation of instruments in isomorphic MCQs that require separate training. The pouring of the results of the implementation in the form of scientific work also still requires ongoing assistance.

Keywords: assessment for learning, physics teacher, high school

\section{PENDAHULUAN}

Asesmen merupakan salah satu faktor yang berpengaruh terhadap kualitas dan hasil pembelajaran (Popham, 2008: 5). Asesmen membantu guru mendapatkan informasi tentang kemajuan dan kesulitan belajar siswa serta memanfaatkannya untuk mengambil keputusan dalam pembelajaran. Asesmen juga dapat memberikan feedback pada siswa terkait perkembangan belajarnya. Feedback berdasarkan asesmen ini memberikan langkah yang perlu dilakukan untuk siswa untuk mencapai kompetensi yang telah ditetapkan (Cowie \& Bell, 2002: 82). Pentingnya asesmen berkelanjutan dalam pembelajaran ditekankan secara eksplisit dalam Peraturan Menteri Pendidikan Nasional nomor 20 tahun 
2007 tentang Standar Penilaian Pendidikan (Peraturan Menteri Pendidikan Nasional RI Nomor 20, 2007).

Salah satu permasalahanpenilaian dalam pembelajaran fisika di Kota Malang saat ini adalah kurang terselenggaranya assesment for learning yang memberikan feedback langsung terhadap kemajuan belajar peserta didik. Pelaksanaan asesmen pembelajaran pada saat ini lebih didominasi oleh asesmen sumatif (assesment of learning) dibandingkan dengan asesmen assesment for learning. Hasil penelitian awal Kusairi (2010) menunjukkan bahwa beberapa hal yang menyebabkan assesment for learning sulit dilaksanakan diantaranya 1) jumlah peserta didik yang besar, 2) assesment for learning menyita waktu dalam menyiapkan instrumen maupun pelaksanaan, 3) implementasi assesment for learning memerlukan keterampilan khusus, 4) belum adanya sistem otomasi/software yang dikembangkan untuk mendukung assesment for learning. Penyelenggaraan assesment for learning yang mensyaratkan pemberian Realtime feedback sulit dilakukan oleh guru tanpa adanya dukungan instrumen dan teknologi yang memadai (Sorensen \&Takle, 2005).

Berdasarkan hasil observasi dan wawancara dengan beberapa guru fisika SMA di Malang yang terhimpun dalam forum musyawarah guru, ada beberapa permasalahan yang sering dihadapi dalam menyelenggarakan pembelajaran. Permasalahan tersebut antara lain 1) guru masih belum bisa melaksanakan penilaian yang efektif khususnya terkait dengan kurikulum 2013. Sebagai contoh, dalam standard penilaian kurikulum 2013 terdapat penilaian formatif formal dimana guru perlu memberikan tes, segera melakukan koreksi, melakukan analisis hasil, serta memberikan balikan (feedback) dan remedial secepatnya. Hal ini sulit untuk diterapkan karena guru menghadapi jumlah siswa yang besar; 2) Guru tidak memiliki rekaman data penilaian secara tertulis dan data tentang kegiatan penilaian formatif terutama formatif informal. Hal ini terjadi mengingat sulitnya mengelola data penilaian dalam jumlah yang banyak dan diperlukan waktu tersendiri untuk perekaman dan analisisnya; 3) Terbatasnya waktu interaksi dan tanya jawab antara guru dengan siswa, dan antara siswa dengan siswa; 4) Belum tersedianya wahana bagi siswa untuk memperoleh berbagi sumber belajar khususnya dalam bentuk teks dan media berbantuan komputer; dan 5) Belum tersedianya media pembelajaran berbantuan komputer yang dapat memperkaya khasanah pengetahuan siswa tentang penilaian dan praktik pembelajaran abad 21 .

Dalam upaya meningkatkan kemampuan guru SMA yang berkualitas, diperlukan pemanfaatan teknologi informasi untuk mendapatkan kekuatan dan kelemahan belajar siswa (Bell \& Cowie, 2002). Survey awal menunjukkan bahwa hampir seluruh siswa telah memiliki handphone berbasis android yang bisa mengakses internet dimanapun dan kapanpun. Hal ini memudahkan siswa untuk dapat terlibat secara aktif dalam melakukan pembelajaran. Keterlibatan siswa dalam pembelajaran diyakini merupakan salah satu faktor penentu keberhasilan siswa (Clyde, et al., 2005). Prinsip yang demikian diartikan sebagai hubungan timbal balik antara siswa dan guru, dimana siswa diharapkan menerima informasi, mengkaji, menelaah dan mengkonstruksi pengetahuannya secara mandiri. Oleh karena itu, dalam abad informasi global dan teknologi informasi seperti saat ini, harus dimanfaatkan oleh guru untuk meningkatkan kualitas pembelajaran. Perkembangan sains dan teknologi serta perubahan kondisi sosial masyarakat yang sangat pesat mengharuskan guru untuk meningkatkan kemampuan dan keahliannya. Selain itu, penggunaan model sains teknologi dalam proses pembelajaran akan lebih memotivasi siswa untuk mendalami materi pembelajaran.

Dengan demikian, pemanfaatan aplikasi computer berbasis web merupakan salah satu solusi pembelajaran yang bisa meningkatkan kualitas pembelajaran (Leighton \& Gierl 2007; Lingard, 2005; Lowry, 2005). Hal ini dimaksudkan agar siswa tidak mengalami kesulitan dalam memahami materi yang diajarkan oleh guru. Kesulitan belajar yang tidak 
mendapatkan penanganan, mengakibatkan prestasi belajar siswa menjadi rendah. Penelitian yang dilakukan oleh Kusairi (2010), menemukan bahwa analisis data menggunakan komputer membantu siswa SMA belajar dan membantu guru mengambil keputusan. Model pembelajaran Hybrid on line yang dikembangkan oleh Kusairi (2011) terhadap pembelajaran di perguruan tinggi memiliki manfaat yang besar dalam pembelajaran, antara lain sebagai berikut. 1) Membantu penyelenggaraan perkuliahan menjadi lebih efektif, 2) Peserta didik dapat memperoleh materi kuliah tambahan di internet sehingga wawasan mereka lebih luas, 3) Manajemen pembelajaran menjadi lebih teratur dan praktis, dan 4)Peserta didik dapat berdiskusi baik dengan guru maupun sesama peserta didik lain di luar waktu pelajaran. Turkmen \&Usta (2007) melaporkan bahwa penggunaan e-tools membantu mengelola tugas penilaian dan menghemat waktu. Penggunaan moda kuis dan feedback membantu peserta didik menguasai konsep lebih baik. Implementasi self assessment dalam assessment for learning juga dilaporkan berpengaruh positif terhadap belajar peserta didik. Berdasarkan penelitian tersebut, maka diperlukan penguasaan terhadap model asesmen yang memanfaatkan teknologi dan informasi. Oleh karena itu, sangat diperlukan adanya workshopasesmen pembelajaran bagi guru-guru FISIKA SMA di Kota Malang untuk meningkatkan kualitas asesmen dan pembelajaran.

Penelitian yang dilakukan oleh kelompok penelitian asesmen di Prodi Pendidikan Fisika FMIPA UM telah mengembangkan model hybrid on-line untuk meningkatkan assessment for learning dalam perkuliahan (Kusairi \& Sujito, 2014). Penelitian juga telah mengembangkan Tryout dan Webvoting yang terbukti dapat meningkatkan kualitas perkuliahan (Kusairi \& Sujito, 2016). Tujuan kegiatan ini adalah alih teknologi assessment for learning berbantuan jaringan internet untuk meningkatkan kualitas pembelajaran guru fisika di Kota Malang yang tergabung dalam MGMP Fisika Kota Malang. Target luaran kegiatan adalah meningkatnya kemampuan guru fisika SMA di kota Malang khususnya guru mitra diantaranya adalah sebagai berikut. 1) Memanfaatkan Tryout dan Webvoting dalam assessment for learning. 2) Mengimplementasikan assessment for learning berbantuan Tryout dan Webvoting dalam pembelajaran fisika. 3) Menuangkan hasil pelaksanaan assessment for learning berbantuan Tryout dan webvoting dalam bentuk karya ilmiah.

\section{METODE}

Bentuk kegiatan yang dilakukan adalah workshop pengembangan assessment for learningberbantuan jaringan komputer atau WEB. Workshop dimulai dengan penjelasan secara umum tentang peranan assessment for learning dan dilanjutkan pemanfaatan Try Out dan Web Vooting. Untuk mendukung pengembangan kapasitas guru dalam mengembangkan asesmen pembelajaran, maka materi dalam kegiatan ini adalah sebagaimana Tabel 1 berikut. Pada pertemuan 1 dibahas tentang peranan assessment for learning. Terlebih dahulu guru diminta mengisi angket persepsi tentang pelaksanaan asesmen di sekolah. Diskusi kemudian dilanjutkan dengan berbagi pengalaman tentang pelaksanaan asesmen yang biasa dilakukan di sekolah. Pemaparan tentang Assessment for Learning dimaksudkan agar guru menyadari bahwa tujuan utama penilaian adalah membantu siswa belajar bukan sekedar menilai hasil belajar. Pada kegiatan ini dikenalkan juga tentang elemen kunci assessment for learning yang meliputi penyampaian tujuan pembelajaran yang jelas, membangun komunikasi, pemberian feedback yang meningkatkan belajar, memberikan tanggung jawab yang tinggi pada pembelajar, dan modifikasi proses belajar berdasarkan informasi kekuatan dan kelemahan siswa. Dengan pertemuan ini, diharapkan guru telah memahasmi peranan asesmen yang sesungguhnya 
dan guru diberikan kesempatan untuk mengimplementasikannya di sekolah. Salah satu contoh presentasi penguatan asesmen adalah sebagaimana Gambar 1 di bawah.

Tabel 1. Materi Workshop

\begin{tabular}{|c|l|c|l|}
\hline No & \multicolumn{1}{|c|}{ Materi } & $\begin{array}{c}\text { Waktu @50 } \\
\text { menit }\end{array}$ & \multicolumn{1}{|c|}{ Ket } \\
\hline 1 & Kebijakan asesmen dan assessment for learning & 2 jam & Pertemuan 1 \\
\hline 2 & Five Keys element Assessment for learning & 4 jam & Pertemuan 1 \\
\hline 3 & Implementasi assessment for learning & 8 jam & Di Sekolah \\
\hline 4 & Pengenalan dan penggunaan aplikasi Webvoting & 6 jam & Pertemuan 2 \\
\hline 5 & Pengembangan Butir isomorfik & 2 jam & Pertemuan 2 \\
\hline 6 & Implementasi aplikasi Webvoting & 8 jam & Di Sekolah \\
\hline 5 & Pengenalan dan penggunaan Tryout & 8 jam & Pertemuan 3 \\
\hline 6 & Pendampingan penggunaan Tryoutdan penulisan & 8 jam & Di Sekolah \\
\hline
\end{tabular}

\section{What is assessment?}

\section{- The word 'assess' comes from the Latin verb 'assidere' meaning 'to sit beside'.}
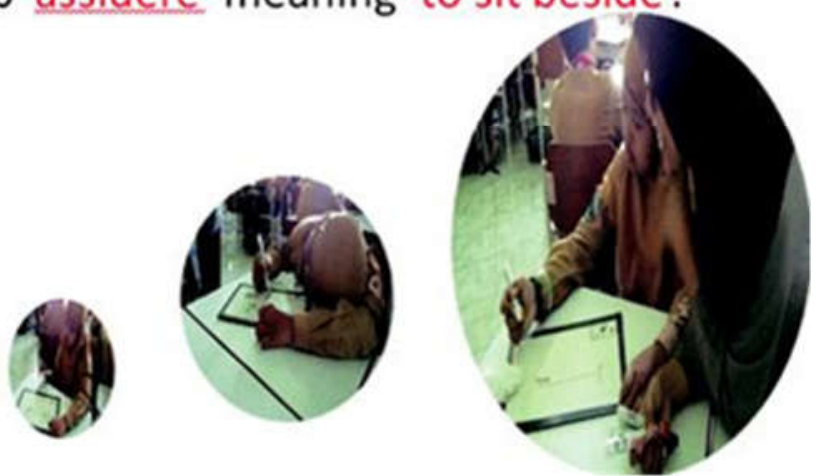

Gambar 1. Contoh presentasi assessment for learning

Pertemuan ke 2 dilakukan 2 minggu setelah pertemuan pertama. Pada pertemuan kedua, pelatihan diawali dengan diskusi tentang berbagai kesulitan dan kendala yang dihadapi oleh guru dalam melaksanakan assessment for learning. Salah satu masalah yang dialami adalah memberikan feedback untuk menigkatkan belajar siswa. Masalah ini menjadi factor penguat perlunya dikenalkan aplikasi Webvoting. Aplikasi webvoting adalah aplikasi yang dapat mengeluarkan pertanyaan, mengoreksi dan menyampaikan persentase jawaban benar secara real time. Dengan aplikasi ini guru akan dapat dengan mudah mendapatkan informasi tentang kemajuan belajar siswa-siswanya. Kegiatan ini juga ditindaklanjuti dengan pemanfaatan di sekolah dimana webvoting dipadukan dengan assessment for learning. Diimplementasikan dengan menggunakan aplikasi Try Out dan Webvoting.

Sebelum pertemuan ke 3 tentang aplikasi tryout dilaksanakan, terlebih dahulu diidentifikasi permasalah yang dialami guru fisika dalam melaksanakan assessment for learning dengan bantuan webvoting di sekolah. Sebagian besar guru merasa bahwa webvoting sangat berguna namun sayangnya mereka belum dapat membuat soal mereka sendiri. Aplikasi tryout dapat menbantu guru dalam mengidentifikasi letak kesulitan belajar siswa sekaligus dapat mengkreasi soal untuk keperluan webvoting. Pertemuan ke 3 diawali dengan guru mencoba perangkat tryout dimana mereka berperan seperti seorang siswa. Dengan demikian, hal ini berguna ketika mereka memanfaatkan aplikasi tryout 
untuk dipadukan dalam assessment for learning. Pada bagian ini juga diberikan wawasan tentang penulisan ilmiah pada peserta pelatihan. Kegiatan diakhiri dengan tugas disekolah untuk mengkombinasikan assessment for learning, webvoting dan tryout.

Pada setiap akhir pertemuan, guru-guru peserta pelatihan diminta mengisi kuesioner baik berkaitan dengan asesmen maupun berkaitan dengan pelaksanaan pelatihan. Data hasil kuesioner dianalisis secara persentase untuk disampaikan pada pserta pelatihan sebagai balikan maupun untuk keperluan pelaporan. Dalam pelatihan ini, selain dosen juga dilibatkan beberapa orang mahasiswa. Peranan mahasiswa adalah membantu bapak ibu guru terutama berkaitan dengan kesulitan penggunaan teknologi informatika dan computer. Salah satu contoh suasana pelatihan adalah sebagaimana Gambar 2 di bawah.

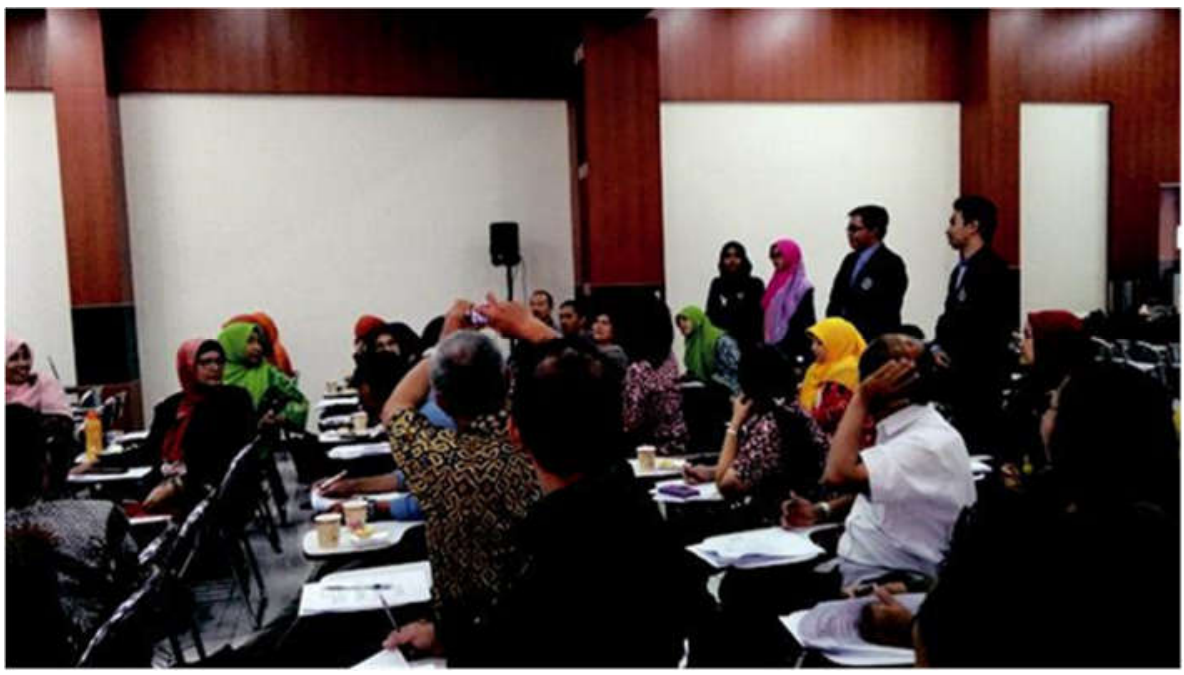

Gambar 2. Suasana Pelatihan tatap muka

\section{HASIL DAN PEMBAHASAN}

Hasil pengujian yang dilakukan dengan mitra, untuk mencari bahan yang digunakan, temperatur, debit udara blower dan kecepatan putaran dinamo. Bahan yang digunakan sebagai segel menggunakan plastik PET dengan ketebalan $1 \mathrm{~mm}$. Temperatur yang digunakan $90^{\circ} \mathrm{C}-100^{\circ} \mathrm{C}$ dan debit udara blower yang diatur menggunakan dimmer dengan rata-rata kecepatan udara $450 \mathrm{~L} / \mathrm{min}$. Sedangkan putaran dinamo yang digunakan untuk memutar botol menggunakan dimer kecepatan yaitu $3 \mathrm{~m} / \mathrm{s}$. Dari parameter-parameter tersebut ditetapkan dari hasil uji coba yang telah dilakukan diambil parameter yang paling terbaik diukur dari hasil kwalitas segel yang didapatkan. Persepsi peserta pelatihan tentang asesmen dapat dilihat pada Tabel 2 berikut.

Berdasarkan tabel di atas, dapat dilihat bahwa peserta pelatihan memiliki persepsi bahwa asesmen merupakan bagian penting pembelajaran. Peserta merasa telah memahami asesmen dengan baik, namun peserta menganggap masih perlu belajar tentang asesmen. Peserta masih banyak yang memandang asesmen sebagai alat menjustifikasi hasil belajar siswa, namun peserta juga tertarik untuk mengetahui kesulitan belajar siswa-siswanya. Peserta juga menyadari bahwa asesmen sangat menyita waktu, sementara hanya sebagian peserta pelatihan yang telah menggunakan teknologi informasi.

Pelatihan 1 dimulai dengan berbagi pengalaman tentang pelaksanaan asesmen di sekolah. Sedikit berbeda dengan hasil kuesioner, ternyata persepsi dosen tentang asesmen masih terbatas pada ulangan harian, ujian tengah semester, dan ujian akhir semester. Beberapa peserta mengemukakan bahwa mereka juga melaksanakan quis dalam pembelajaran. Pemahaman bahwa tujuan utama penilaian adalah membantu siswa belajar masih kurang. Jadi, seperti kebanyakan guru-guru yang lain, asesmen diidentikkan dengan asesmen of learning. 
Tabel 2. Persepsi Peserta Pelatihan terhadap Asesmen

\begin{tabular}{|l|l|c|c|c|c|}
\hline No & \multicolumn{1}{|c|}{ Uraian } & SS & S & TS & STS \\
\hline 1 & $\begin{array}{l}\text { Menurut saya asesmen/penilaian merupakan bagian } \\
\text { penting dalam pembelajaran }\end{array}$ & 29 & 6 & 0 & 0 \\
\hline 2 & $\begin{array}{l}\text { Asesmen/Penilaian saya lakukan utamanya untuk } \\
\text { melaporkan hasil belajar siswa }\end{array}$ & 13 & 17 & 3 & 2 \\
\hline 3 & $\begin{array}{l}\text { Asesmen/Penilaian penting untuk menjustifikasi } \\
\text { kesuksesan belajar siswa }\end{array}$ & 9 & 19 & 5 & 2 \\
\hline 4 & $\begin{array}{l}\text { Asesmen/Penilaian berguna untuk mengetahui siapa saja } \\
\text { siswa yang mengalami masalah belajar }\end{array}$ & 25 & 10 & 0 & 0 \\
\hline 5 & $\begin{array}{l}\text { Saya telah memahami dengan baik hakikat asesmen } \\
\text { formatif/assessment for learning }\end{array}$ & 6 & 20 & 8 & 1 \\
\hline 6 & $\begin{array}{l}\text { Saya merasa perlu belajar lebih banyak tentang asesmen } \\
\text { formatif/asesmen for learning }\end{array}$ & 23 & 12 & 0 & 0 \\
\hline 7 & $\begin{array}{l}\text { Saya kira pelaksanaan penilaian sangat menyita waktu } \\
\text { dalam pembelajaran }\end{array}$ & 1 & 9 & 20 & 5 \\
\hline 8 & $\begin{array}{l}\text { Saya telah menggunakan teknologi komunikasi dan } \\
\text { komputer dalam melaksanakan Asesmen/Penilaian }\end{array}$ & 7 & 17 & 9 & 2 \\
\hline
\end{tabular}

Kegiatan kemudian dilanjutkan dengan pemaparan konsep assessmen for learning dimana asesmen merupakan bagian tak terpisahkan dalam pembelajaran. Asesmen tidak hanya dilakukan pada akhir siklus pembelajaran melainkan bisa dilakukan pada keseluruhan proses pembelajaran dalam rangka memantau dan membantu siswa belajar. Untuk mengimplementasikan konsep asesmen for learning dikenalkan elemen kunci sebagaimana contoh tayangan pada Gambar 3 berikut. Elemen-elemen dasar tersebut perlu diintegrasikan dalam pengembangan RPP.

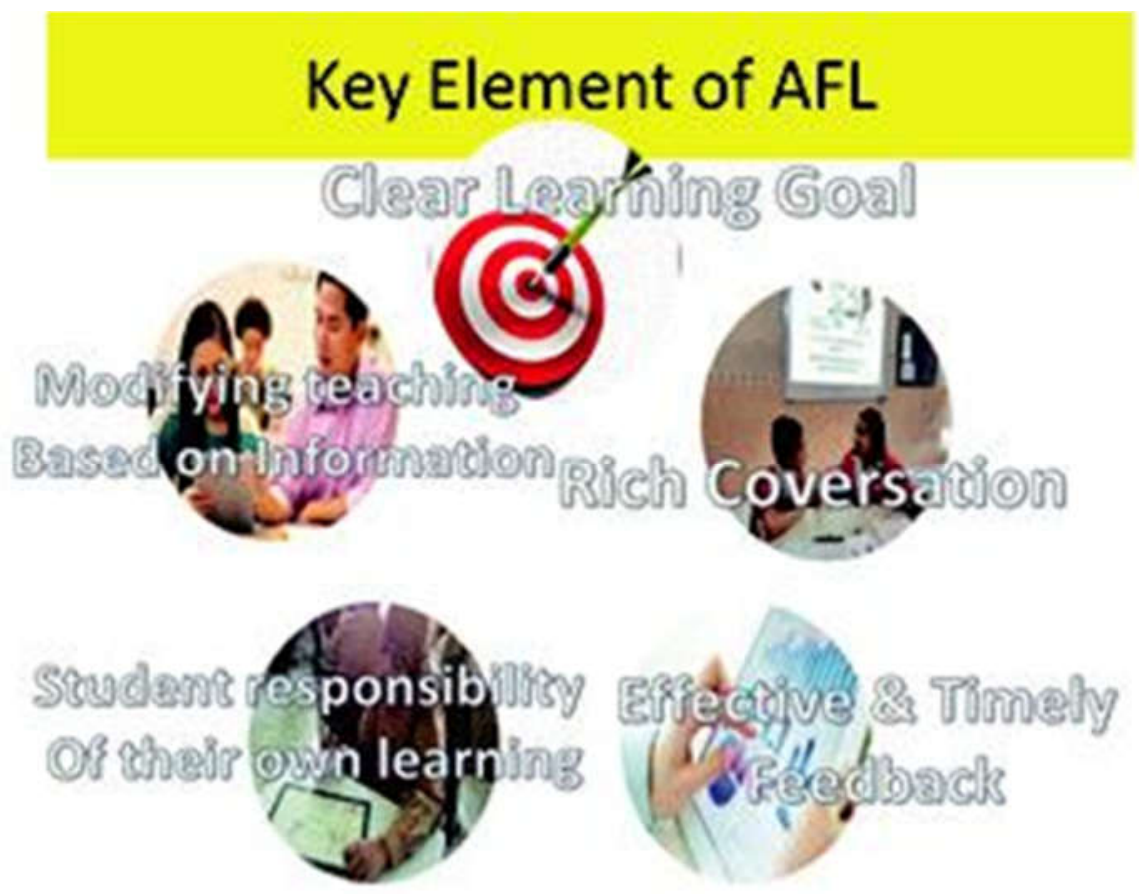

Gambar 3. Tayangan Key Elemen AFL

Pada pertemuan ke 2, ditemukan bahwa pemberian feedback yang tepat waktu merupakan kesulitan dalam pelaksanaan asesmen. Webvoting diperkenalkan sebagai salah 
satu solusi. Pelatihan dimulai dengan ujicoba webvoting dengan guru masuk ke system sebagai siswa. Dengan demikian guru akan mendapatkan pengalaman bagaimana webvoting dapat membantu belajar siswa. Pada tahapan berikutnya, guru juga didaftarkan sebagai pengguna untuk dilaksanakan di sekolah. Salah satu hasil ujicoba adalah sebagaimana Gambar 4 berikut. Pada pertemuan ke 3 dilakukan pelatihan aplikasi Tryout.

Sebuah balok digantung di bawah atap rumah menggunakan tali seperti pada Gambar di bawah. Di antara gaya-gaya yang ada pada gambar tersebut, yang menunjukkan pasangan gaya aksi-reaksi adalah.

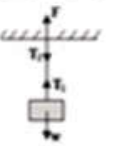
A. T1 dan W
B. $\mathrm{T} 1$ dan $\mathrm{T} 2$
C. T2 dan F
D. F dan W
E. T2 dan W

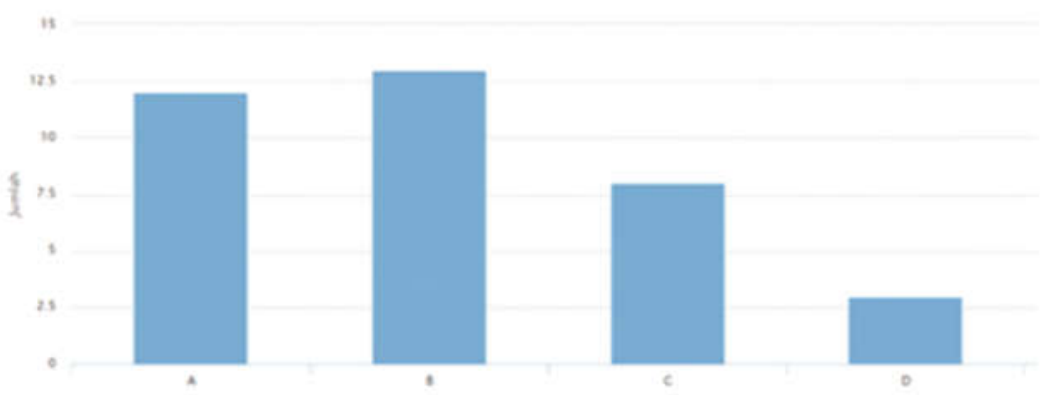

Gambar 4. Hasil Respon Guru pada Webvoting

\section{DAMPAK DAN MANFAAT}

Setelah pelatihan, guru-guru diminta mengisi kuesioner tentang persepsi mereka terhadap penggunaan Tryout dan Webvoting. Tabel 2 menunjukkan ringkasan persepsi guru. Respon guru menunjukkan bahwa webvoting dan tryout dapat membantu asesmen yang dilakukan oleh guru. Beberapa komentar peserta workshop adalah sebagai berikut. 1) Model ini bagus untuk mendiagnosa ketuntasan belajar siswa. Masih perlu belajar membuat soal, terutama untuk fungsi sebagai guru. 2) Model tes fisika berbantuan komputer sangat memudahkan guru dalam melakukan penilaian. Namun sebagai guru perlu banyak berlatih. 3) Model ini sangat membantu guru. Apalagi guru pengajar ada tugas lain yang tidak bisa hadir di kelas. Model ini bisa mengalihkan kebiasaan siswa yang sering menggunakan media lebih ke arah positif. 4) Model tes fisika berbantuan IT/komputer bisa mempermudah guru dalam mengidentifikasi ketuntasan belajar siswa. 5) Bagus, dapat membantu guru dalam melakukan penelitian. 
Tabel 2. Persepsi Guru tentang webvoting

\begin{tabular}{|c|c|c|c|c|c|}
\hline \multirow[t]{2}{*}{ No } & \multirow{2}{*}{ PERNYATAAN } & \multicolumn{4}{|c|}{ PERSENTASE } \\
\hline & & SS & $\mathbf{S}$ & KS & TS \\
\hline 1 & $\begin{array}{l}\text { Informasi tentang ketuntasan belajar setiap siswa dibutuhkan } \\
\text { guru dalam proses pembelajaran }\end{array}$ & 77 & 23 & 0 & 0 \\
\hline 2 & $\begin{array}{l}\text { Informasi tentang ketuntasan belajar kelompok siswa (kelas) } \\
\text { dibutuhkan guru untuk mengambil keputusan dalam } \\
\text { pembelajaran. }\end{array}$ & 77 & 23 & 0 & 0 \\
\hline 3 & $\begin{array}{l}\text { Feedback atau umpan balik tentang ketuntasan belajar siswa } \\
\text { yang diberikan oleh guru dibutuhkan siswa untuk mengelola } \\
\text { proses }\end{array}$ & 73 & 27 & 0 & 0 \\
\hline 4 & $\begin{array}{l}\text { Feedback atau umpan balik tentang ketuntasan belajar siswa } \\
\text { yang diberikan oleh guru sebaiknya segera diinformasikan } \\
\text { guru pada seluruh siswa }\end{array}$ & 86 & 14 & 0 & 0 \\
\hline 5 & $\begin{array}{l}\text { Proses mengidentifikasi/mendiagnostik dan mendapatkan } \\
\text { informasi tentang ketuntasan belajar siswa mudah dilakukan } \\
\text { oleh guru. }\end{array}$ & 23 & 68 & 5 & 0 \\
\hline 6 & $\begin{array}{l}\text { Model Tes Fisika berbantuan computer TRYOUT dapat } \\
\text { membantu guru dalam mengidentifikasi ketuntasan belajar } \\
\text { siswa. }\end{array}$ & 59 & 36 & 0 & 0 \\
\hline 7 & $\begin{array}{l}\text { Model Tes Fisika berbantuan computer TRYOUT dapat } \\
\text { membantu guru dalam memberikan umpan balik tentang } \\
\text { ketuntasan belajar }\end{array}$ & 68 & 27 & 0 & 0 \\
\hline 8 & $\begin{array}{l}\text { Butir soal isomorfik dalam Model Tes diagnostic fisika } \\
\text { berbantuan computer dapat dikembangkan oleh guru. }\end{array}$ & 32 & 64 & 0 & 0 \\
\hline 9 & $\begin{array}{l}\text { Model Tes Diagnostic Fisika berbantuan computer } \\
\text { WEBVOTING dapat membantu guru dalam } \\
\text { mengidentifikasi ketuntasan belajar siswa. }\end{array}$ & 45 & 50 & 0 & 0 \\
\hline 10 & $\begin{array}{l}\text { Model Tes Diagnostic Fisika berbantuan computer } \\
\text { WEBVOTING dapat membantu guru dalam memberikan } \\
\text { umpan balik tentang ketuntasan belajar kepada siswa. }\end{array}$ & 64 & 36 & 0 & 0 \\
\hline 11 & $\begin{array}{l}\text { Model Tes Diagnostik Fisika berbantuan computer } \\
\text { TRYOUT bermanfaat untuk mendukung pembelajaran. }\end{array}$ & 68 & 32 & 0 & 0 \\
\hline 12 & $\begin{array}{l}\text { Model Tes Diagnostik Fisika berbantuan computer } \\
\text { WEBVOTING bermanfaat untuk mendukung pembelajaran } \\
\text { khususnya pembelajaran fisika. }\end{array}$ & 68 & 32 & 0 & 0 \\
\hline
\end{tabular}

Pada akhir pelatihan peserta diminta mengisi kuesioner. Hasil kuesioner adalah sebagaimana Tabel 3 berikut. Secara keseluruhan peserta pelatihan memandang positif pelatihan yang dilakukan. Beberapa masukan peserta pelatihan adalah sebagai berikut. 1) Menyediakan meja yang lebih besar sehingga mudah untuk mengoperasikan laptop, 2) Waktu pelatihan ditambah, 3) Tetap dilaksanakan kegiatan rutin pelatihan untuk menambah wawasan guru dalam proses pembelajaran, 4) Kami mengharap untuk diadakan pelatihan pelatihan yang lain untuk pengembangan ilmu dan diberikan dengan sabar, 5) Ada tindak lanjut pelatihan berikutnya.

Kegiatan pelatihan telah berhasil meningkatkan pengetahuan dan keterampilan guru fisika dalam menyelenggarakan asesmen dengan bantuan jaringan computer. Kegiatan ini perlu diperluas mengingat bahwa meskipun guru memiliki persepsi bahwa mereka telah menyelenggarakan asesmen, pada kenyataannya kebanyakan guru hanya 
melaksanakan asesmen sumatif (assessment of learning). Pemahaman guru tentang makna asesmen akan berdampak pada kualitas asesmen dan juga pembelajaran. Kegiatan pelatihan ini memiliki kelemahan dimana materi yang disampaikan terlalu banyak dan waktu yang tersedia dalam pelatihan terbatas. Direkomendasikan agar pelatihan berikutnya dapat memberikan durasi waktu yang cukup atau membahas materi tahap demi tahap diiringi dengan pendampingan praktik di sekolah.

Tabel 3. Rekapitulasi hasil kuesioner pelatihan

\begin{tabular}{|l|l|c|c|c|c|}
\hline No & \multicolumn{1}{|c|}{ Uraian } & SS & S & TS & STS \\
\hline 1 & $\begin{array}{l}\text { Materi pelatihan sesuai dengan kebutuhan saya } \\
\text { sebagai guru fisika }\end{array}$ & 73.53 & 23.53 & 0.00 & 0.00 \\
\hline 2 & Pelaksanaan pelatihan ini dikelola dengan baik & 55.88 & 38.24 & 2.94 & 0.00 \\
\hline 3 & $\begin{array}{l}\text { Para fasilitator memfasilitasi dengan baik kegiatan } \\
\text { pelatihan ini }\end{array}$ & 64.71 & 29.41 & 2.94 & 0.00 \\
\hline 4 & $\begin{array}{l}\text { Tempat dan akomodasi pelatihan ini nyaman dan } \\
\text { memadai }\end{array}$ & 67.65 & 32.35 & 0.00 & 0.00 \\
\hline 5 & $\begin{array}{l}\text { Secara keseluruhan pelaksanaan pelatihan bermanfaat } \\
\text { bagi guru fisika }\end{array}$ & 82.35 & 17.65 & 0.00 & 0.00 \\
\hline
\end{tabular}

\section{KESIMPULAN}

Telah dilakukan pelatihan untuk meningkatkan kapasitas guru-guru fisika dalam menyelenggarakan asesmen dengan bantuan computer atau WEB. Pelatihan meliputi materi assessment for learning, webvoting dan tryout serta kombinasi implementasinya dalam pembelajaran fisika. Pelatihan sangat bermanfaat bagi guru-guru fisika dalam meningkatkan kualitas asesmen pembelajaran, kualitas layanan pada siswa dan pada akhirnya berdampak pada kualitas pembelajaran secara keseluruhan.

Pelatihan semacam ini perlu disebarluaskan agar dapat dinikmati oleh guru-guru fisika yang lain. Mengingat materi yang cukup banyak, perlu disediakan waktu yang cukup agar guru benar benar dapat menggunakan semua aplikasi dengan baik. Pelatihan keterampilan penggunaan ICT juga disarankan sebelum guru mengikuti pelatihan semacam ini.

\section{UCAPAN TERIMA KASIH}

Ucapan terima kasih kami ucapkan kepada LP2M UM yang telah membiayai kegiatan ini, Dekan FMPA UM, dan Ketua MGMP Fisika Kota Malang yang telah mendukung terselenggaranya kegiatan ini.

\section{REFERENSI}

Bell, B. \& Cowie, B. (2002). Formative assessment and science education, New Zealand: Kluwer Academic Publisher.

Clyde, W., \& Delohery, A. (2005). Using Technology in Teaching. London: Yale University Press DEPDIKNAS. (2007). Peraturan Menteri Pendidikan Nasional Nomor 20

Tahun 2007, tentang Standar Penilaian Pendidikan.

Kusairi, S. (2011). Analisis Asesmen Formatif Fisika Berbantuan Komputer, Disertasi, tidak diterbitkan, UNY.

Kusairi S. (2010). Analisis asesmen formatif fisika berbantuan computer. Disertasi tidak diterbitkan, UNY, Yogyakarta. 
Kusairi S. (2011). Pengembangan soal isomorpik bermakna untuk mengidentifikasi miskonsepsi siswa. Laporan penelitian. Tidak diterbitkan. Malang.

Kusairi S dan Sujito (2016), Implementasi Tes diagnostic Fisika, Laporan Penelitian, Tidak diterbitkan

Popham, W. J. (2008). Transformative assessment. Virginia: Association of supervision and curriculum development (ASCD).

Lowry, R. (2005). Computer aided self assessment: An effective tool. Chemistry Education Research and Practice, 2005, 6 (4), 198-203

Lambert, L., \& Lines, D. (2000). Understanding assessment: Purpose, perceptions,

practice. New

York: Routledge Falmer.

Lingard, M. (2005). Introducing computer-assisted assessment: Consideration for the new practitioner [versi electronik], Investigation in University Teaching and Learning, 2,2 .

Sorensen, E. K., \& Takle, E. S. (2005). Investigating knowledge building dialogues in networked communities of practice. A collaborative learning endeavor across cultures. Interactive Educational Multimedia (10), 50-60.

Turkmen, H., \& Usta, E. (2007). The role of learning cycle approach overcoming misconception in science [versi electronik]. Kastamonu Education Journal, 15(2), 491-500. 